\title{
A brief discussion on environmental quality monitoring required in a central sterile supply department: Evidence from a cancer center in eastern India
}

\author{
Debabrata Basu MSc, DHM (1), Arijit Das BCom and John Debdutta Rozario BSc \\ Tata Medical Center, New Town, Kolkata, West Bengal, India
}

To the Editor-The consistent delivery of products and services according to established standard is called quality. The concept of quality relates to the degree or grade of excellence of a product or service. Moreover, quality requires effort and participation from everyone in the facility, and to achieve optimal service, time is required to develop, implement, and monitor quality-control processes. The environmental quality monitoring system in a hospital's central sterile supply department (CSSD) can reduce unnecessary sterilization cost and increase the shelf life of medical devices. The basic functions of a CSSD are cleaning, disinfection, and sterilization of a large number of reusable medical devices in a healthcare institution. The entire decontamination processes (from cleaning to sterilization) can only be safe if the surrounding environment is clean and controlled. ${ }^{1,2}$ For proper sterility assurances there are four different environmental quality monitoring systems are discussed: water quality monitoring, air quality monitoring, carbolization and sterility testing.

In the CSSD, purified water is required for cleaning, disinfection, and sterilization purposes. The water used in the CSSD should have low surface tension and should be free from minerals (ie, low total dissolved solids, hardness, and conductivity) and microbes. Mineralfree water is needed to avoid salt deposition on surgical instruments and electrical elements such as heaters (inside the boiler), so that this equipment can run well for a long time. Furthermore, water should be free from microorganisms to avoid the formation of pyrogens after disinfection and sterilization. Therefore, identifying and testing the source of water and the purification system are very important for achieving a high-quality water supply. For water-quality monitoring, periodic chemical tests (ie, chlorine level $0.2-0.5 \mathrm{ppm}$ and $\mathrm{pH}, \sim 8$ ) and microbiological tests (eg, for Pseudomonas and coliform bacteria) are required. ${ }^{3}$

The CSSD is mainly divided into 3 zones: a dirty zone, a packaging zone, and a sterile zone. Purified and moisture-free air is essential for preparing sterile materials and preserving them for a long time. According to the international standard, the temperature of a CSSD (including sterile storage) should be $20-22^{\circ} \mathrm{C}$ and the relative humidity should be $30 \%-60 \%$. Air should always move from the sterile zone to the dirty zone to avoid cross contamination. The clean air must be particle free, and the air-filter pore size should range between $0.05 \mu \mathrm{m}$ and a maximum of $\leq 10 \mu \mathrm{m}$. Furthermore, tests for differential air pressure (minimum, 2.5 Pascals), air velocity (minimum, 2,500 cfm), air exchange rate ( $\geq 10$ per hour), and air microbiology (measuring bacterial and

Author for correspondence: Debabrata Basu, Email: debabrata.basu@tmckolkata.com Cite this article: Basu D, Das A, and Rozario JD. (2020). A brief discussion on environmental quality monitoring required in a central sterile supply department: Evidence from a cancer center in eastern India. Infection Control \& Hospital Epidemiology, 41: 624-625, https://doi.org/10.1017/ice.2020.41 fungal colony) are required to minimize air impurities in the sterile zone. $^{4}$

The process of cleaning articles with antiseptic solution is called carbolization. This process includes daily cleaning of floor, walls and ceiling, tables and trolleys, and other equipment in the CSSD. Stainless steel equipment is cleaned using a neutral enzymatic solution because chloride solution may induce rust, but other areas and equipment are cleaned using a hypochloride solution (ie, 150 ppm chlorine concentration). Cleaning should be carried out twice daily to ensure a clean and dust-free environment. A daily audit should be required to assess cleaning performance. ${ }^{5}$

Sterility testing is one of the outputs of environmental quality monitoring that examines how clean the CSSD is. It is widely considered that "worldwide sterility maintenance is event related rather than time related." But in some exceptions, such as poor design, incorrect process flow, faulty equipment or technique, or poor environmental conditions, sterility can be maintained on a time-related basis. In time-related sterility assurance, 2 times are maintained related to product shelf life: manufacturing date and expiry date. After sterilization, the sample is kept in sterile storage until the date of expiry, then the sample is sent to the microbiology department for culture. To confirm shelf life (based on work practices, sterile barrier system, storage, and environmental conditions), sterility testing is the only method that can ensure that a product has retained its sterility in a certain environmental condition. ${ }^{6,7}$

The total costs of environmental quality monitoring systems are high. Here, we have adopted a cost calculation method from a cancer center in eastern India where the total costs of environmental quality monitoring systems are based on standard operational procedures (SOPs) and that have been standardized by the hospital infection control committee. The frequency of monitoring may vary from 1 day to 1 month, but the standards are quite similar to international standards. A comprehensive cost analysis is provided as a reference in Table 1. If test results are unacceptable according to the standard, then continuous assessment is required until satisfactory results are achieved, and this process increases costs as well.

In conclusion, the objective of a hospital CSSD is to provide the right items to the user at the right time, in the right place, and under the right conditions. The CSSD plays an important role in infection control practices where a well-designed and well-equipped department combine with an efficient staff to achieve high-quality work. However, providing a sterile item in the right condition to the user's area requires not only good work practices (skills or technique) but also good environmental conditions. The challenge is to ensure that environmental monitoring systems are used routinely (according to the standard) for proper sterility assurance and that human intervention and faulty documentation do not hinder the process. $^{8}$ 
Table 1. Cost of Consumables Used for Central Sterile Supply Department (CSSD) Environmental Quality Monitoring Purposes

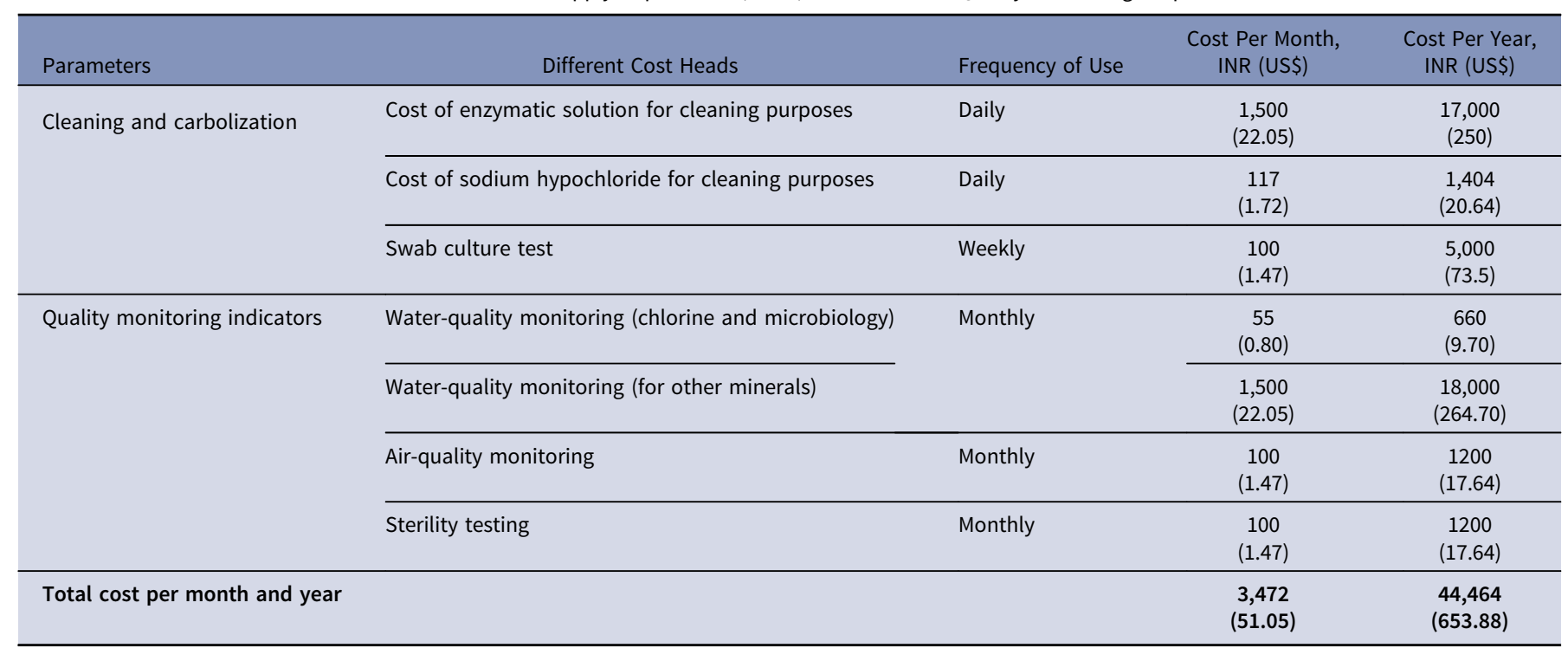

Note. INR, Indian rupees.

Acknowledgment. None.

Financial support. No financial support was provided relevant to this article.

Conflicts of interest. All authors report no conflicts of interest relevant to this article.

Supplementary material. To view supplementary material for this article, please visit https://doi.org/10.1017/ice.2020.41

\section{References}

1. Central service technical manual. International Association of Healthcare Central Service Materiel Management website. https://www.iahcsmm.org/ publications/central-service-technical-training-8/crcst-8th-ed-manual-contents. html. Accessed August 22, 2019.

2. Guideline for disinfection and sterilization in healthcare facilities. Centers for Disease Control and Prevention website. http://www.cdc.gov/hicpac/ disinfection sterilization/1700recommendations.html. Published 2008, Accessed February 6, 2020.
3. Bhalchandra R, Chandy M, Ramanan VR, et al. Role of water quality assessments in hospital infection control: experience from a new oncology center in eastern India. Indian J Pathol Microbiol 2014;57:435-438.

4. Clean rooms and associated controlled environments, part 2: specifications for testing and monitoring to prove continued compliance with ISO 14644-1. International Standards Organization website. https://www.iso.org/obp/ui/ \#iso:std:iso:14644:-2:ed-1:en. Accessed August 22, 2019.

5. KEYA KALP national guidelines for clean hospitals. Ministry of Health and Family Welfare Government of India website. https://mohfw.gov.in/ sites/default/files/7660257301436254417_0.pdf. Accessed August 22, 2019.

6. Sterilization of medical devices, microbiological methods, part 2: tests of sterility performed in the definition, validation and maintenance of a sterilization process. International Standards Organization website. https://www.iso.org/ obp/ui/\#iso:std:iso:11737:-2:en. Accessed August 22, 2019.

7. European expert condemns the re-use of sterilization packaging. Irish Decontamination Institute website. http://www.deconidi.ie/html/educ/ articles/educarticle_0001.htm. Accessed August 22, 2019.

8. Basu D, Bhattacharya S, Mahajan A, Ramanan VR, Chandy M. The importance of the central sterile supply department in infection prevention and control. Infect Control Hosp Epidemiol 2014;35:1312-1314.

\title{
Reprocessing of single-use medical devices and their associated problems: an experience from a cancer center in eastern India
}

\author{
Debabrata Basu $\mathrm{MSC}^{1}$ (1), Mousumi Dhara $\mathrm{MA}^{2}$ and Sanjay Kishore Dutta BCom ${ }^{1}$ \\ ${ }^{1}$ Central Sterile Supply Department, Tata Medical Center, Kolkata, India and ${ }^{2}$ Materials Department, Tata Medical Center, Kolkata, India
}

Author for correspondence: Debabrata Basu, E-mail: debabrata.basu@tmckolkata.com Cite this article: Basu D, Dhara M, and Dutta SK. (2020). Reprocessing of single-use medical devices and their associated problems: an experience from a cancer center in eastern India. Infection Control \& Hospital Epidemiology, 41: 625-627, https://doi.org/ $10.1017 /$ ice.2020.54
To the Editor-Transmission of infectious agents can occur through unclean and unsterile medical devices. Breakdown of sterility of medical devices may lead to the transmission of bacterial and viral pathogens, including those associated with multidrug resistance. Costly medical devices must be reprocessed, and the decontamination process must be conducted under stringent quality 